\title{
Correlation for Nusselt Number and Friction Factor for Solar Air Heater Having Absorber Roughened by Chamfered-square Elements
}

\author{
Man Singh Azad ${ }^{1, *}$, Apurba Layek ${ }^{2}$ \\ ${ }^{1}$ CSIR-Central Mechanical Engineering Research Institute, Durgapur, India \\ ${ }^{2}$ Department of Mechanical Engineering, National Institute of Technology, Durgapur, India
}

Email address:

msazada@gmail.com (M. S. Azad)

${ }^{*}$ Corresponding author

\section{To cite this article:}

Man Singh Azad, Apurba Layek. Correlation for Nusselt Number and Friction Factor for Solar Air Heater Having Absorber Roughened by Chamfered-square Elements. International Journal of Fluid Mechanics \& Thermal Sciences. Vol. 5, No. 2, 2019, pp. 50-62. doi: $10.11648 /$ j.jifmts.20190502.13

Received: April 9, 2019; Accepted: May 20, 2019; Published: June 12, 2019

\begin{abstract}
The idea of introducing artificial roughness on absorber plate to improve the thermal performance of a solar air heater is very common now days. The technique uses the concept of providing artificial roughness by imbedded element in the absorber plate of the heater. Diagonally chamfered cuboids have been used as roughness element in the current study. A numerical study is performed to investigate the enhancement of the thermo-hydraulic performance of the heater for the various affecting parameters such as Relative Roughness Pitch (Transverse and Longitudinal) of 6 to 14, cross section of cuboids from $8 \mathrm{~mm}$ to $14 \mathrm{~mm}$ and relative roughness height of 0.44 to 0.088 . The range of Reynolds number used in this study was 5000 to 22500. During the study a constant heat flux of $1000 \mathrm{~W} / \mathrm{m}^{2}$ on the absorber plate was considered. The standard k- $\varepsilon$ turbulence model with enhanced wall treatment of the ANSYS FLUENT software has been used for numerical computation and to handle the flow turbulence. The Nusselt number and the average friction factor are determined for different values of relative roughness pitch and cross sectional areas of the roughness element. Using calculated computational data correlations for Nusselt number as well as friction factor have been developed as a function of flow and roughness parameters for solar air heaters. The predicted and computational values of Nusselt number and friction factor show a good agreement.
\end{abstract}

Keywords: Solar Air Heater, Artificial Roughness, Computational Fluid Dynamics (CFD), ANSYS FLUENT, Correlations

\section{Introduction}

With rapidly growing population, industrialization, and transportation demand for energy is being continuously rising. The continuous use of limited stock of fossil fuels on the earth, felt energy starvation globally. The uncontrolled use of fossil fuel resulted serious environmental problem, which forced the scientific community to think new and alternate ways to fulfill the future energy demand. The freely and abundantly available solar energy has capability to curb these energy demands among the all sources of renewable energy. The solar insolation gets absorbed by absorber plat of solar air heater, where solar insolation is converted into heat and then heat is transferred to the air blowing under it. The hot air gets application in space heating or process heating. The rate of heat transfer between the absorber plate and the blowing air even for the turbulent flow is very low hence the heat transfer co efficient of a solar air heater (SAH) is very poor. Numerous techniques have so far been used to improve the heat transfer rate and the thermal efficiency of $\mathrm{SAH}$. Initially, packed bed techniques were used by researchers [1]. Thereafter, fins were applied in SAH to improve the performance [2-5]. Artificially roughened absorber plate is latest technique that is being used [6-8]. Among these the easiest and the most acceptable method to enhance the thermal performance is the employ of artificially roughened absorber plate for the SAH.

The laminar sub-layer is formed on the conventional absorber plate, which is cause of thermal resistance to heat transfer. To destroy the laminar sub-layer, artificial roughness 
is employed on absorber plate to improve the convective heat transfer by creating turbulence in the flow. This led to increase in friction losses and to overcome from itmore power is required by the fan or blower. Various researchers have investigated the thermo-hydraulic performances of solar air heater embedded with different types of artificial roughness elements with an emphasis on the effect of different roughness parameters. These are comprehensively reviewed by Kumar et al. and not repeated here for the purpose of brevity [9].

Vyas and Shringi performed Computational fluid dynamics (CFD) based analysis on the solar air heater having baffles as roughness elements to investigate thermal performance and found 2.23 times more heat transfer compared to smooth plates [10]. Vikrant et al. investigated numerically the performance of solar air heater equipped with circular transverse wire ribs as roughness element and found considerable heat transfer enhancement [11]. Prasad and Saini investigated the performance of solar air heater having small diameter wire as roughness element and found considerable enhancement in Nusselt number and friction coefficient at relative roughness pitch of 10 [12]. Karwa et al. investigated V-discrete and Vcontinuous rib as roughness element experimentally and reported that discrete ribs and $60^{\circ}$ ribs perform better than the continuous rib and $45^{\circ}$ ribs respectively [13]. Rasool et al. performed CFD based numerical analysis of SAH with doublepass channels having variable rib shapes and found boot shape ribs performing better then house shape and conventional square shape ribs [14].

It is observed that majority of the works available in the literature except a few are experimental. Anumerical analysis can be used successfully as an alternative to the expensive experimental investigation and in quick time several different orientations can be studied for their effectiveness in order to improve the thermal efficiency of SAH. Accordingly, a novel approach is adopted here to use diagonally chamfered cuboid elements to be inserted artificially on the absorber plate of the SAH for making it rough. A numerical study based on the CFD approach is proposed to investigate the effectiveness of the roughness element for improved thermal performance of the heater.

\section{Material and Method}

Diagonally chamfered square elements of $8 \mathrm{~mm}$ to $14 \mathrm{~mm}$ arm length and 2 to $4 \mathrm{~mm}$ height have been used as artificial roughness elements and inserted inner-side of the absorber plate. Various relative roughness pitches (transverse and longitudinal) have been used for investigation. The hydraulic diameter (D) of SAH duct used for investigation is $45 \mathrm{~mm}$. A uniform heat flux of $1000 \mathrm{~W} / \mathrm{m}^{2}$ has been applied on the absorber plate for entire investigation. Reynolds number ranging from (Re) 5000 to 22500 , have been used for study to observe the effect of the roughness on Nusselt number and friction factor as the SAH generally operates at the same range.

The detail of the roughness is explained in Figure 1. The roughness is provided only on absorber plate and remaining all three sides of test duct is considered as smooth surfaces. A SAH duct having dimensions as $2100 \mathrm{~mm}$ long (L), 200mm width (W) and $25 \mathrm{~mm}$ height $(\mathrm{H})$ have been used for CFD analysis. The aspect ratio 8 was constant for entire study. The flow domain was divided in three sections i.e., entry section, entry section and test section. To minimize the end effects the entry section $(725 \mathrm{~mm})$ and exit section $(325 \mathrm{~mm})$ of the flow domain were kept sufficiently large.

A secondary flow is assume to be happen as the roughness geometry is inclined in the transverse direction of air flow, therefore a 3D flow domain have been selected for the study. ICEM CFD (Trade mark) of ANSYS 13.0 is used for meshing of domain in the present work. Finer mesh in the rib region and relatively coarser mesh for other region has been used for accurately examine the flow behavior and heat transfer.

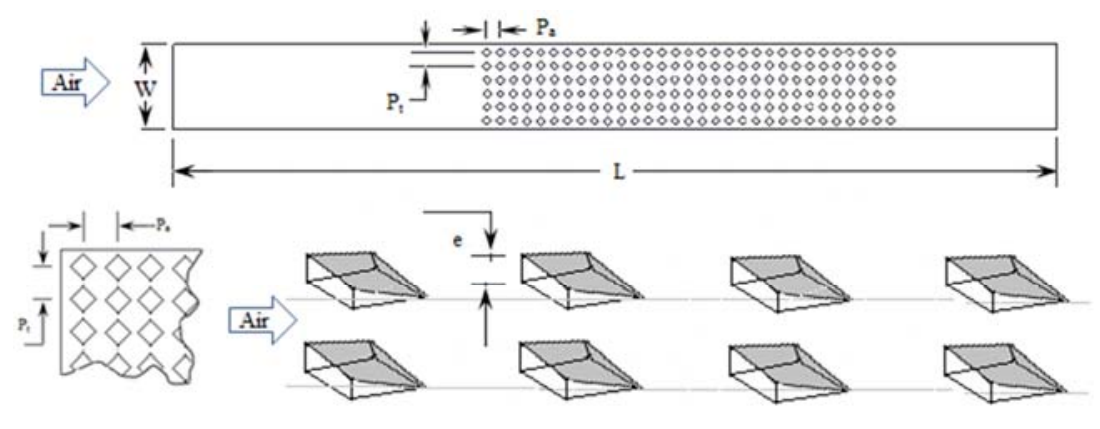

Figure 1. Detailed of the roughness elements.

The system of governing equation consists of the continuity, momentum and energy equations. The governing equations for 3-D domain are shown below:

Continuity equation:

$$
\frac{\partial u}{\partial x}+\frac{\partial v}{\partial y}+\frac{\partial w}{\partial z}=0
$$

Momentum equation:

$$
u \frac{\partial u}{\partial x}+v \frac{\partial u}{\partial y}+w \frac{\partial u}{\partial z}=-\frac{1}{\rho} \frac{\partial p}{\partial x}+v\left(\frac{\partial^{2} u}{\partial x^{2}}+\frac{\partial^{2} u}{\partial y^{2}}+\frac{\partial^{2} u}{\partial z^{2}}\right)
$$




$$
\begin{gathered}
u \frac{\partial v}{\partial x}+v \frac{\partial v}{\partial y}+w \frac{\partial v}{\partial z}=-\frac{1}{\rho} \frac{\partial p}{\partial y}+v\left(\frac{\partial^{2} v}{\partial x^{2}}+\frac{\partial^{2} v}{\partial y^{2}}+\frac{\partial^{2} v}{\partial z^{2}}\right)+g \beta\left(T-T_{\infty}\right) \\
u \frac{\partial w}{\partial x}+v \frac{\partial w}{\partial y}+w \frac{\partial w}{\partial z}=-\frac{1}{\rho} \frac{\partial p}{\partial z}+v\left(\frac{\partial^{2} w}{\partial x^{2}}+\frac{\partial^{2} w}{\partial y^{2}}+\frac{\partial^{2} w}{\partial z^{2}}\right)
\end{gathered}
$$

Energy equation:

$$
u \frac{\partial T}{\partial x}+v \frac{\partial T}{\partial y}+w \frac{\partial T}{\partial z}=\alpha\left(\frac{\partial^{2} T}{\partial x^{2}}+\frac{\partial^{2} T}{\partial y^{2}}+\frac{\partial^{2} T}{\partial z^{2}}\right)
$$

where $\mathrm{u}, \mathrm{v}, \mathrm{w}$ are the components of the fluid velocity in $\mathrm{x}, \mathrm{y}$ and $\mathrm{z}$ directions of the rectangular Cartesian coordinate, $\mathrm{p}$ is the pressure, $\mathrm{T}$ is the temperature and $\mathrm{T} \infty$ is the ambient temperature. The thermo-physical properties are described through the density $(\rho)$, kinematic viscosity $(v)$, thermal diffusivity $(\alpha=k / \rho C p)$ with $k$ being the thermal conductivity and $\mathrm{Cp}$ the specific heat at constant pressure, $\beta$ is the volumetric thermal expansion coefficient and $g$ is the acceleration due to gravity.

In present study ANSYS FLUENT 13.0 has been used as computational tool for CFD analysis of SAH duct. A 3D model of computational domain has been used due to presence of secondary flow in transverse direction. A fully developed, steady and turbulent flow is assumed. It is also assumed that all walls of duct except absorber plate are adiabatic and the working fluid air is incompressible for the test range of SAH. These assumptions were made based on the previous investigations done by the researchers in their experiments. Table 1 shows the thermophysical properties of air and aluminum plate which are working fluid and absorber plate respectively.

Table 1. Thermophysical properties of working fluid and absorber plate.

\begin{tabular}{lll}
\hline Parameter & Air & Absorber plate (aluminium) \\
\hline Specific heat $\left(\mathrm{C}_{\mathrm{p}}, \mathrm{J} / \mathrm{kgK}\right)$ & 1004.9 & 871.00 \\
Thermal conductivity $(\mathrm{k}, \mathrm{W} / \mathrm{mK})$ & 0.02624 & 202.40 \\
Density $\left(\rho, \mathrm{kg} / \mathrm{m}^{3}\right)$ & 1.225 & 2719.00 \\
Viscosity $\left(\mu, \mathrm{N} / \mathrm{m}^{2}\right)$ & $1.846 \times 10^{5}$ & - \\
Thermal expansion coefficient $\left(\beta, \mathrm{K}^{-1}\right)$ & 0.0034 & - \\
\hline
\end{tabular}

The boundary conditions of solution domain were specified as, velocity inlet at inlet and outflow at outlet. The turbulence has been specified by turbulence intensity and hydraulic diameter. The boundary condition applied at absorber plate was constant heat flux. SIMPLE (semiimplicit method for pressure linked equations) algorithm with second order upwind numerical scheme of the governing equations has been used for the pressure-velocity coupling.

\section{Selection and Validation of Model}

It is very essential to choose and validate the best fitted turbulence model for computational analysis. For the smooth duct having same cross section Dittus-Boelter empirical correlation for the Nusselt number and modified Blasius equation for the friction factor have been compared with various turbulence models such as Standard (STD) k- $\varepsilon$ model and Realizable (RLG) k- $\varepsilon$ model [15].

Dittus-Boelter correlation for smooth duct:

$$
N u=0.024 \operatorname{Re}^{0.8} \operatorname{Pr}^{0.4}
$$

Modified Blasius equation:

$$
f_{s}=0.085 \mathrm{Re}^{-0.25}
$$

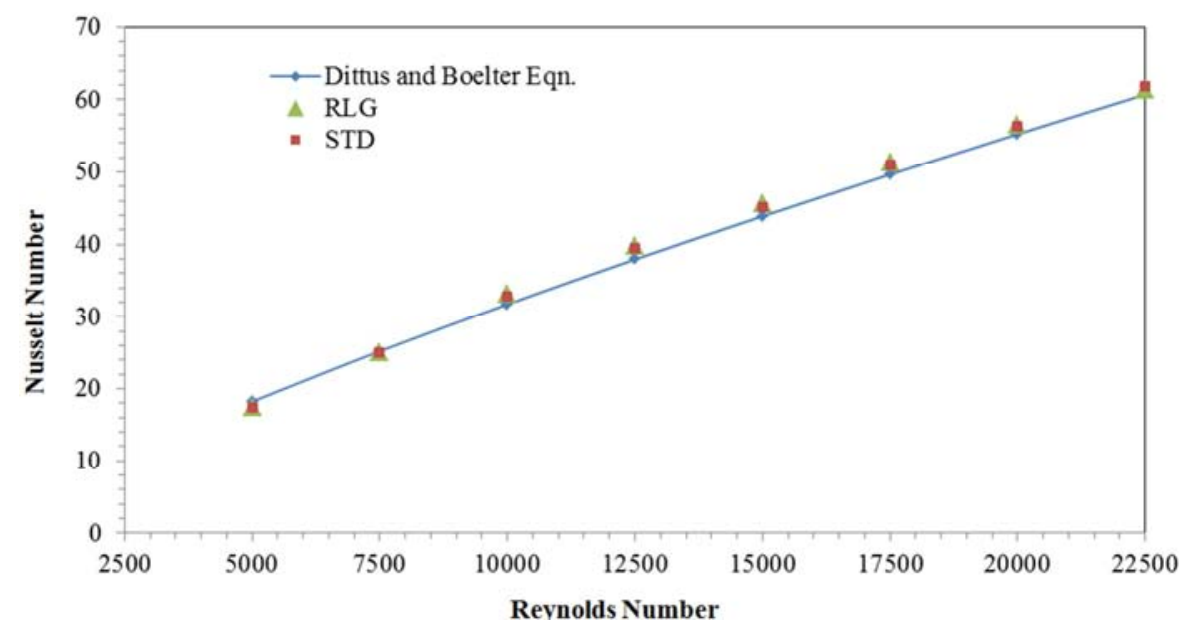

Figure 2. Variation of Nusselt number for different predicted turbulence models with the Dittus-Boelter relation for smooth duct. 
Amongst the all predicted values the STD k- $\varepsilon$ turbulence model have been found best fitted with the Dittus-Boelter empirical correlation and the modified Blasius equation results. It is very clearly shown in, Figure 2 where DittusBoelter correlation results have been compared with various turbulence models for Nusselt number varying with Reynolds number for smooth duct. Similarly it has been shown in, Figure 3 for modified Blasius correlation results, which have been compared with various turbulence models for friction factor varying with Reynolds number. The values found for STD k- $\varepsilon$ turbulence model are within 5\% deviation from the predicted value from the Dittus-Boelter correlation and modified Blasius equation for the Nusselt number and friction factors respectively are within acceptable limit. Based on the validation results STD $\mathrm{k}-\varepsilon$ turbulent model is selected for CFD analysis of SAH duct to get best result.

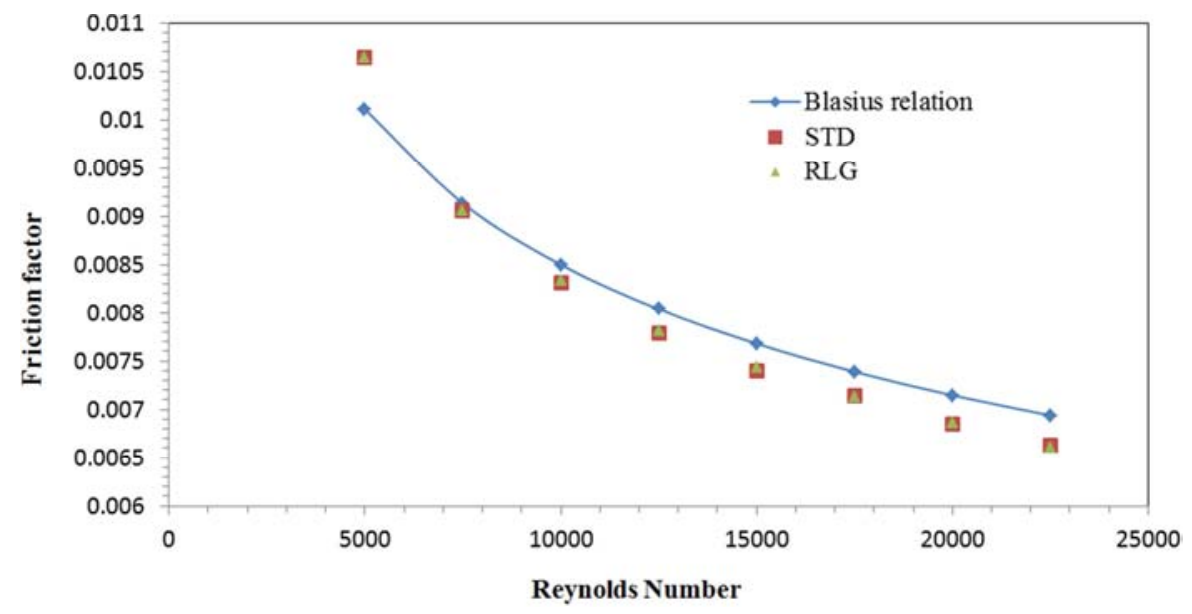

Figure 3. Variation of friction factor for different predicted turbulence models with the modified Blasius relation for smooth duct.

\section{Results and Discussion}

All simulation results found for the roughened absorber plate are presented and compared with the smooth plate result. The improvement in thermo-hydraulic performance of the $\mathrm{SAH}$ for variable flow rate is discussed below.

\subsection{Heat Transfer}

Nusselt number is function of heat transfer and shows the thermal behavior of the SAH. Higher Nusselt number indicates higher heat transfer hence betters the performance of SAH. Figures 4, 5 and 6, shows that the Nusselt number is directly dependent on Reynolds number as Nusselt number increases with increase in is Reynolds number for roughened as well as smooth plate. The variation of Nusselt number with respect to Reynolds number for different relative roughness pitch (longitudinal pitch, $\mathrm{Pa} / \mathrm{e}=6,7,8$ and transverse pitch, $\mathrm{Pt} / \mathrm{e}=4,6,7,8$ ), fixed element size and fixed relative roughness height of the roughness element is shown in Figure 4. The variation of Nusselt number with respect to Reynolds number for different element size having fixed longitudinal and transverse relative roughness pitch $(\mathrm{Pa} / \mathrm{e}=7, \mathrm{Pt} / \mathrm{e}=7)$ and fixed Relative roughness height is shown in Figure 5. Similarly, The variation of Nusselt number with respect to Reynolds number for different relative roughness height having fixed element size and fixed longitudinal and transverse relative roughness pitch $\left(\mathrm{P}_{\mathrm{a}} / \mathrm{e}=6\right.$, $\mathrm{P}_{\mathrm{t}} / \mathrm{e}=6$ ) is shown in Figure 6 .

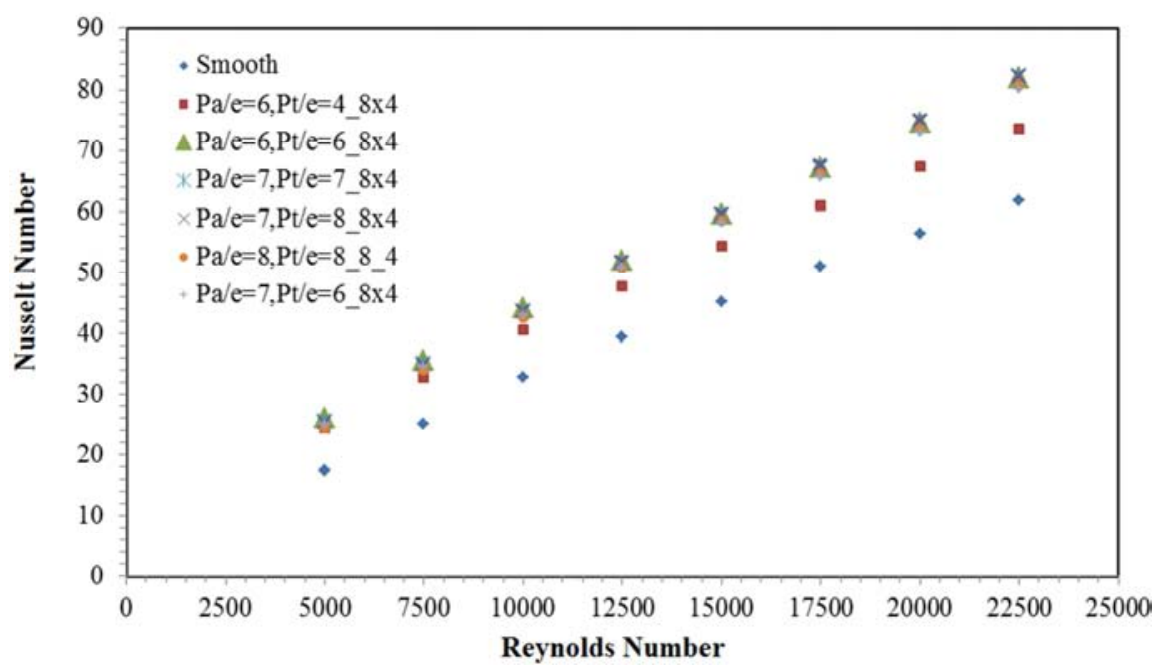

Figure 4. Variation of Nusselt Number for different relative roughness pitches having fixed element size and fixed relative roughness height. 


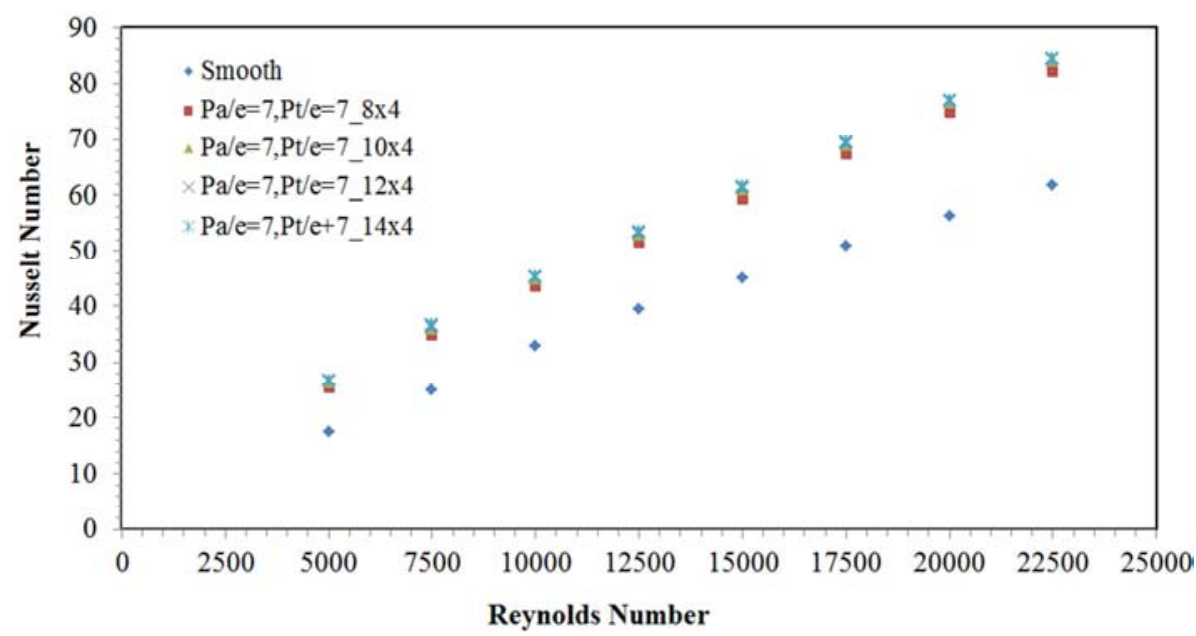

Figure 5. Variation of Nusselt Number for different element size having fixed relative roughness pitch and fixed relative roughness height.

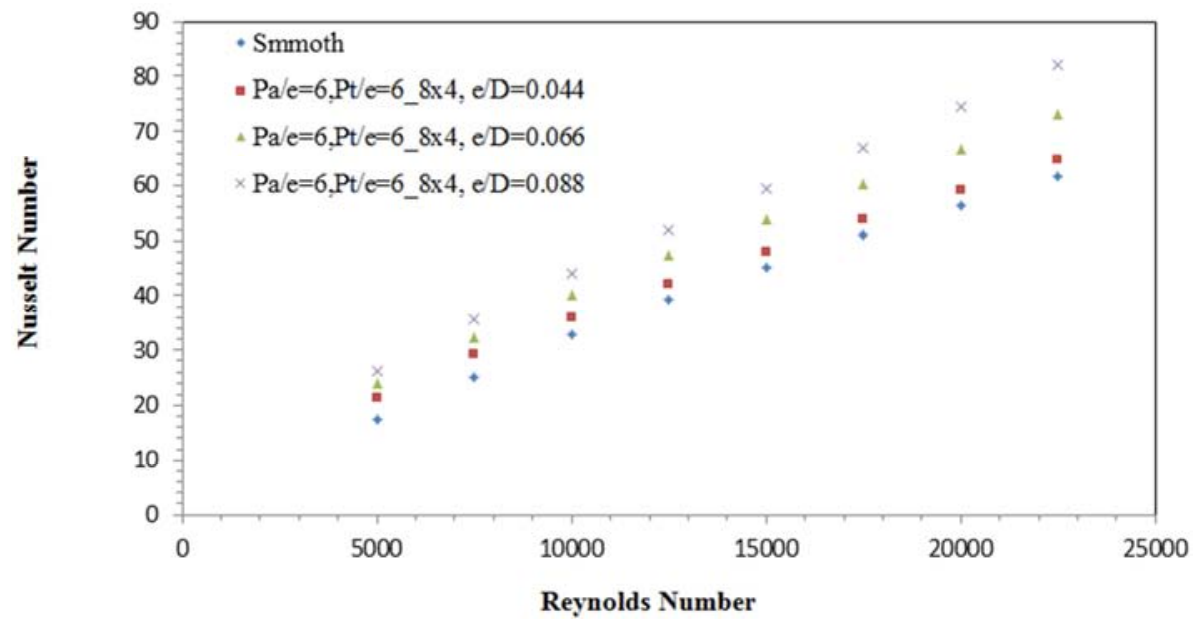

Figure 6. V ariation of Nusselt Number for different relative roughness height having fixed element size and fixed relative roughness pitch.

It can be clearly observed from the above plots that increase in the relative roughness pitch, cross sectional area and relative roughness height, increases the value of Nusselt number. It can be also observed that the Nusselt number increases substantially for the roughened plate in comparison to the smooth plate. Hence, the SAH embedded with the artificial roughness element is found to be more effective in a sense that it provides enhanced thermal performance. The highest Nusselt number is found as 84.3 at $\mathrm{Pa} / \mathrm{e}=7, \mathrm{Pt} / \mathrm{e}=7$ (with element cross section of $12 \times 4$ ).

\subsection{Friction Factor}

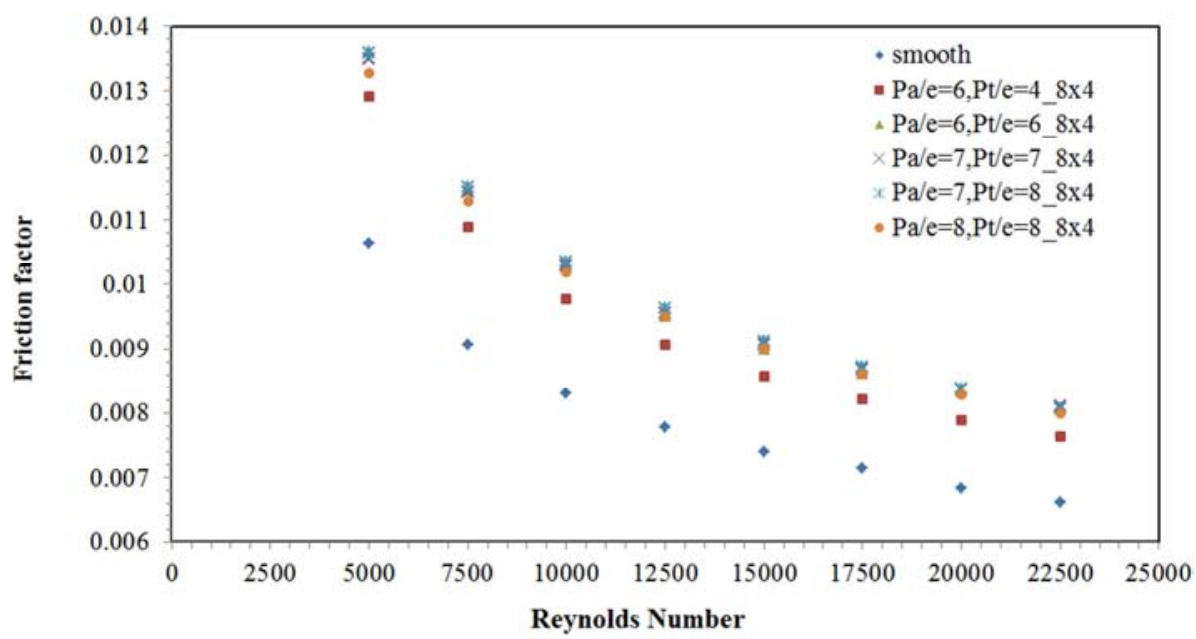

Figure 7. Variation of friction factor for different relative roughness pitch having fixed element size and fixed relative roughness height. 


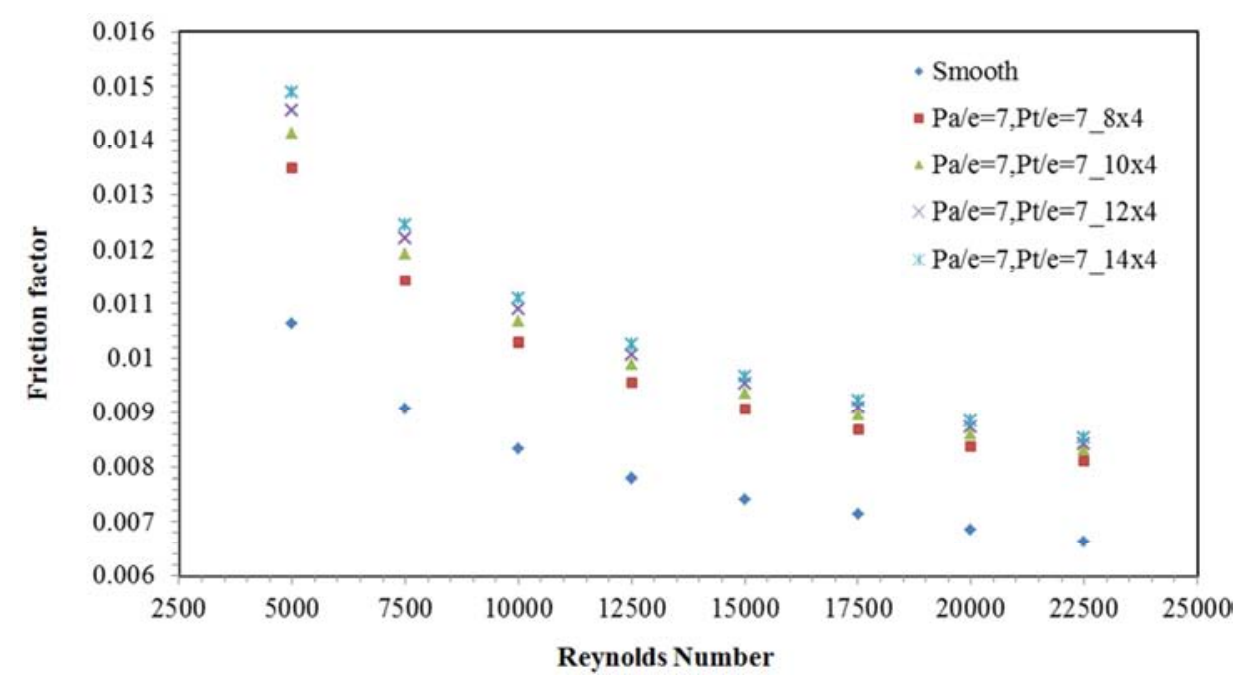

Figure 8. Variation of friction factor for different element size having fixed relative roughness pitch and fixed relative roughness height.

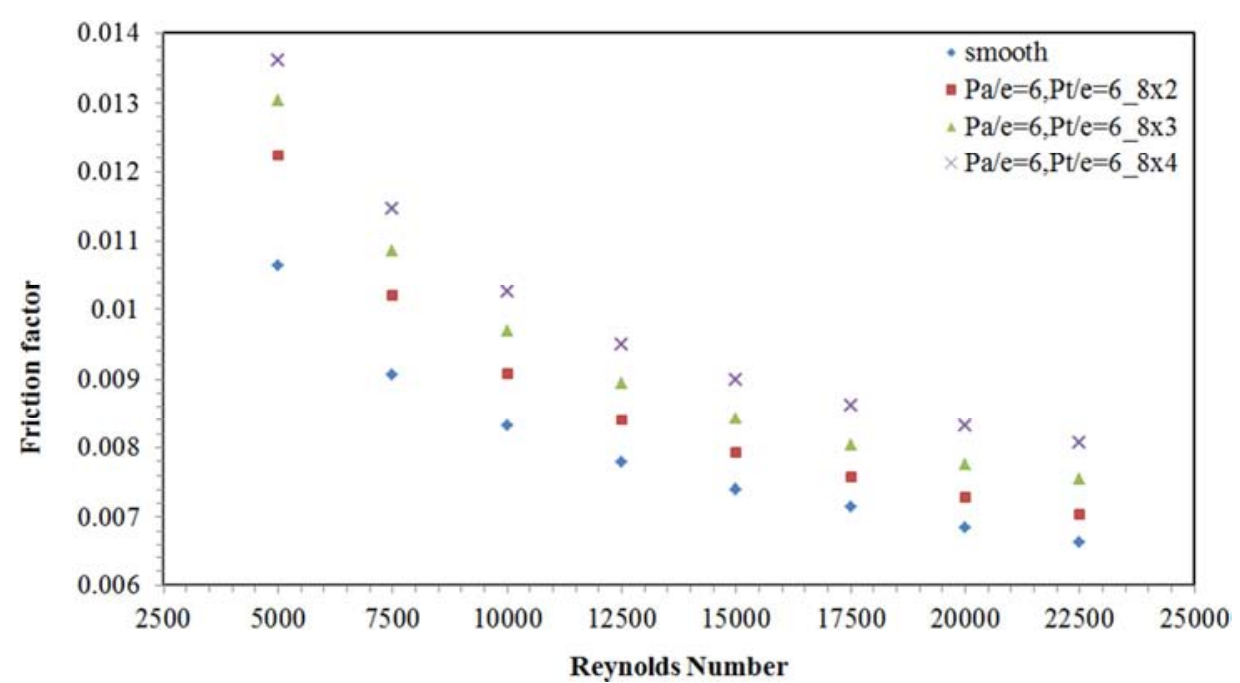

Figure 9. Variation of friction factor for different relative roughness height having fixed element size and fixed relative roughness pitch.

Friction factor affects the thermo-hydraulic performance of $\mathrm{SAH}$. For the better performance of SAH friction factor must be as low as possible and is dependent on Reynolds number. The effect of roughness on friction factor studied is shown in Figures 7, 8 and 9. The variation of friction factor with respect to Reynolds number for different relative roughness pitch (longitudinal pitch, $\mathrm{P}_{\mathrm{a}} / \mathrm{e}=6,7,8$ and transverse pitch, $\left.\mathrm{P}_{\mathrm{t}} / \mathrm{e}=4,6,7,8\right)$ fixed cross section of the roughness element $(8 \times 4$ : arm $x$ height $)$ and fixed relative roughness height is shown in Figure 7. The variation of friction factor with respect to Reynolds number for different element size having fixed longitudinal and transverse relative roughness pitch $\left(\mathrm{P}_{\mathrm{a}} / \mathrm{e}=7, \mathrm{P}_{\mathrm{t}} / \mathrm{e}=7\right)$ and fixed Relative roughness height is shown in Figure 8. Similarly, The variation of friction factor with respect to Reynolds number for different relative roughness height having fixed element size and fixed longitudinal and transverse relative roughness pitch $\left(\mathrm{P}_{\mathrm{a}} / \mathrm{e}=6\right.$, $\mathrm{P}_{\mathrm{t}} / \mathrm{e}=6$ ) is shown in Figure 9 .

It can be clearly observed from the above plots that with increase in Reynolds number the value of the friction factor decreases. This happens due to the suppression of laminar sub-layer for fully developed turbulent flow in the SAH duct. The maximum and minimum friction factor for the roughened absorber plate found is 0.0149 at $\mathrm{Re}=5000$ for $\mathrm{Pa} / \mathrm{e}=7, \mathrm{P}_{\mathrm{t}} / \mathrm{e}=7$ (with cross section $14 \times 4$ ) and 0.00702 at $\mathrm{Re}=22,500$ for $\mathrm{P}_{\mathrm{a}} / \mathrm{e}=7$ and $\mathrm{Pt} / \mathrm{e}=7$ (with cross section $8 \times 2$ ) respectively.

\section{Correlations for Nusselt Number and Friction Factor}

\subsection{Correlations for Nusseltnumber}

For the benefit of researchers it isquite essential to develop the correlations for heat transfer coefficient or nusselt number and friction factor for the all investigated parameters

On the basis of collected data from Simulation, correlations for Nusselt number and friction factor has been developed.

From the investigated simulation result it is very clear that the Nusselt number is fully dependent on roughness parameters studied. The parameters taken into consideration were, $\mathrm{e} / \mathrm{D}, \mathrm{P}_{\mathrm{a}} / \mathrm{e}$, 
$\mathrm{P}_{\mathrm{t}} / \mathrm{e}$, Aand the operating parameter Re. Therefore, the equation for the Nusselt number can be written as:

$$
\mathrm{Nu}=\mathrm{f}(\mathrm{Re}, \mathrm{e} / \mathrm{D}, \mathrm{Pa} / \mathrm{e}, \mathrm{Pt} / \mathrm{e}, \mathrm{A})
$$

With the help of Microsoft excel a regression analysis has been done to develop statistical correlations covering all 136 simulation data found from CFD corresponding to all 17 artificially roughened absorber plates. The Nusselt number plotted as function of Reynolds number has been shown in Figure 10. The best fit equation for Nusselt number found from the Regression analysis is as follows:

$$
N u=A o R e 0.759
$$

Where, coefficient $A_{o}$ is a function of other influencing parameterse $/ \mathrm{D}, \mathrm{P}_{\mathrm{a}} / \mathrm{e}, \mathrm{P}_{\mathrm{t}} / \mathrm{e}$ and $\mathrm{A}$.

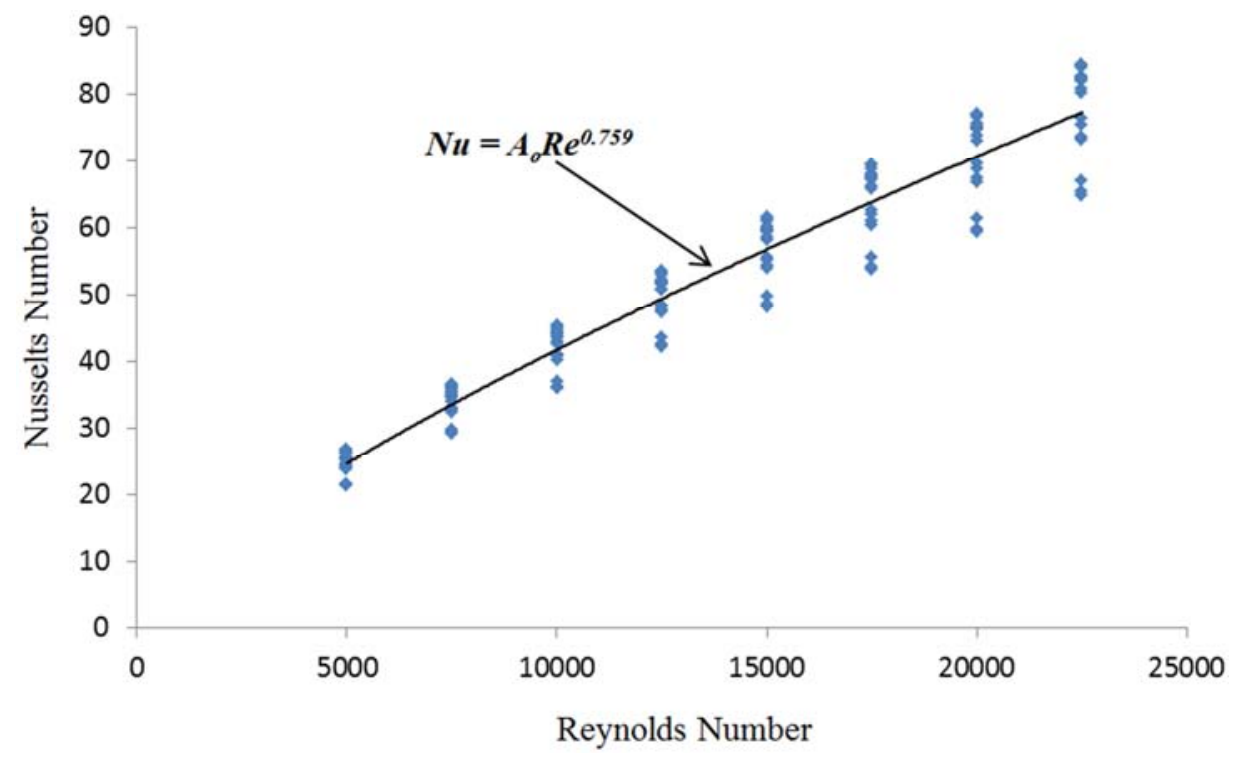

Figure 10. Nusselt number vs. Reynolds number.

Now, taking the relative roughness height of roughness element (e/D) into consideration, the value of $\mathrm{Nu}_{\mathrm{r}} /\left(\mathrm{Re}^{0.759}=\left(\mathrm{A}_{\mathrm{o}}\right)\right.$ corresponding to all values of e/D are plotted, and has been shown in Figure 11.

Now, the regression analysis to find best fit line through these points has been carried out and corresponding equation is as follows:

$$
N u / \operatorname{Re} 0.759=B o(e / D) 0.282
$$

Where, the coefficient $\mathrm{B}_{\mathrm{o}}$ is a function of other remaining influencing parameters $\mathrm{P}_{\mathrm{a}} / \mathrm{e}, \mathrm{P}_{\mathrm{t}} / \mathrm{e}$ and $\mathrm{A}$.

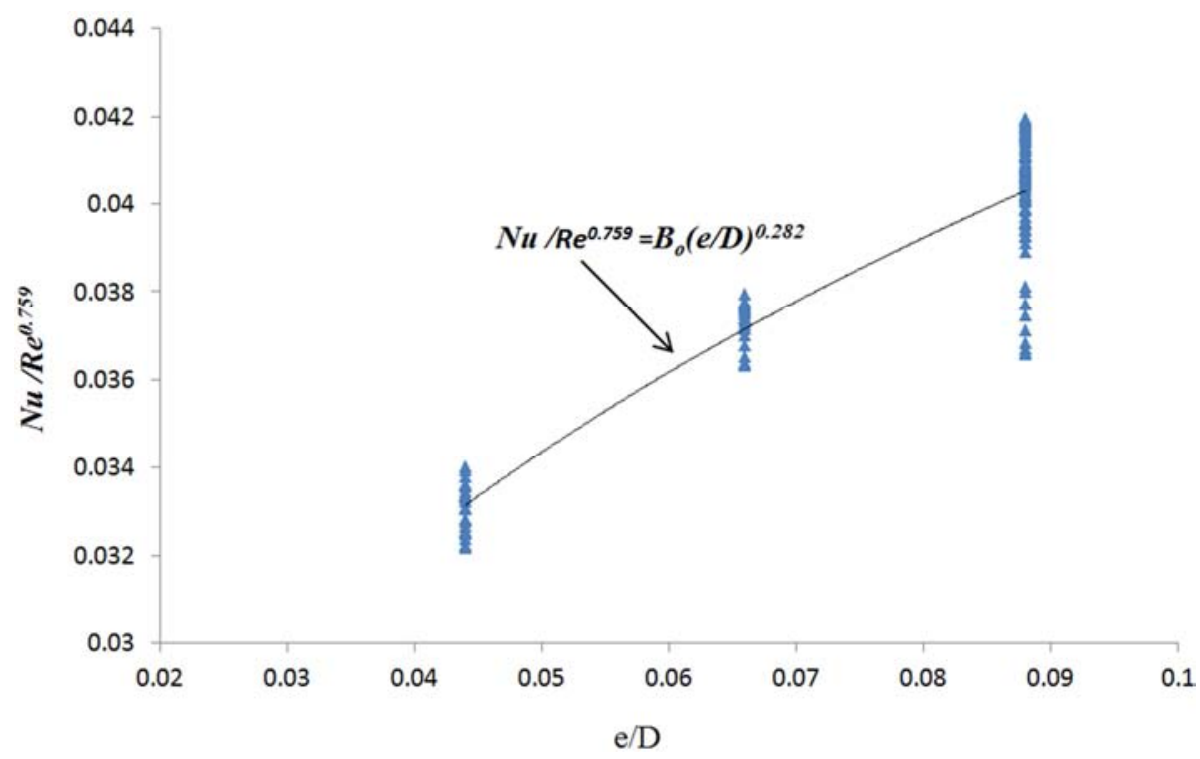

Figure 11. $\left(N u_{r} /\left(R e^{0.759}\right)\right.$ vs. e/D.

Now, taking the arm length of roughness element (A) into consideration, the value of $N u / R e^{0.759} /(e / D)^{0.282}=\left(\mathrm{B}_{\mathrm{o}}\right)$ corresponding to all values of A are plotted, and has been shown in Figure 12. 
Regression analysis to find best fit line through these points has been carried out and corresponding equation is as follows:

$$
\mathrm{Nu} / \operatorname{Re} 0.759 /(\mathrm{e} / \mathrm{D}) 0.282=\operatorname{Co}(\mathrm{A}) 0.282\{-0.096(\operatorname{Ln}(\mathrm{A}) 2\}
$$

Where, The coefficient $C_{o}$ is a function of other remaining influencing parameters $\mathrm{P}_{\mathrm{a}} / \mathrm{e}$ and $\mathrm{P}_{t} / \mathrm{e}$.

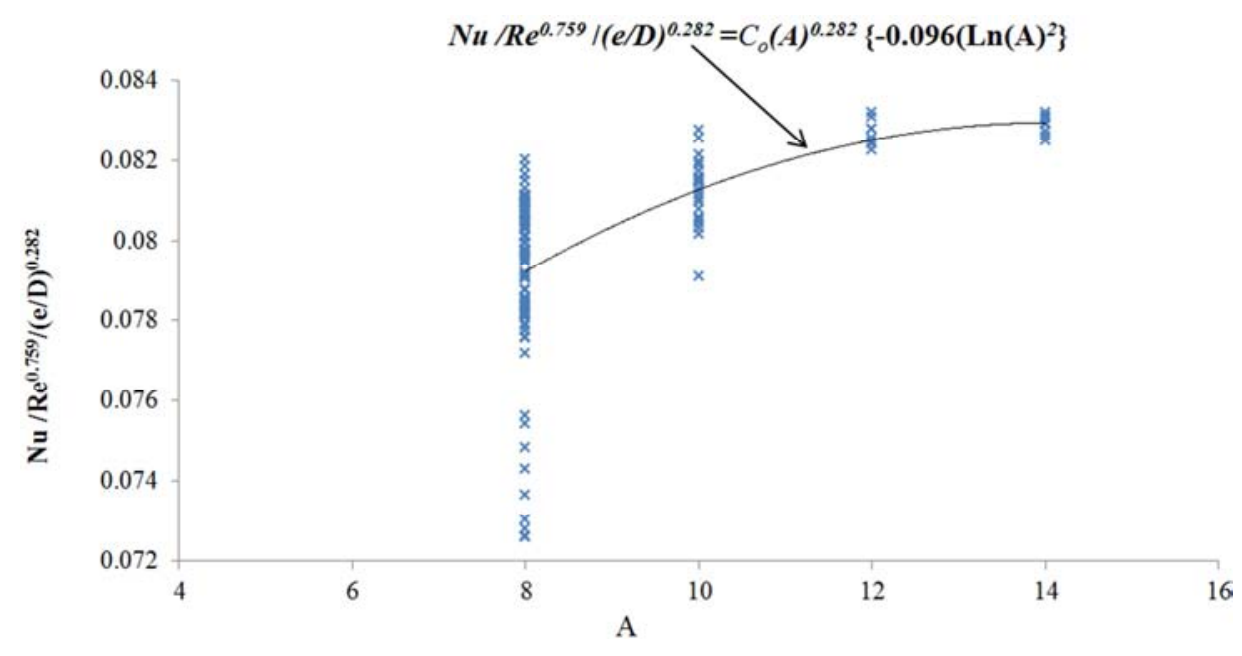

Figure 12. $\left(N u_{r} /\left(R e^{0.759}\right) /(e / D)^{0.282} V S A\right.$.

Now, taking the Relative roughness pitch in Transverse Direction $\left(\mathrm{P}_{\mathrm{t}} / \mathrm{e}\right)$ into consideration, the value of $N u / R e^{0.759} /(e / D)^{0.282}$ $/(A)^{0.282}\left\{-0.096\left(\operatorname{Ln}(\mathrm{A})^{2}\right\}=\left(\mathrm{C}_{\mathrm{o}}\right)\right.$ corresponding to all values of $\mathrm{P}_{\mathrm{t}} / \mathrm{e}$ are plotted, and has been shown in Figure 13.

Regression analysis to find best fit line through these points has been carried out and corresponding equation is as follows:

$$
\mathrm{Nu} / \operatorname{Re} 0.759 /(\mathrm{e} / \mathrm{D}) 0.282 /(\mathrm{A}) 0.282\{-0.096(\operatorname{Ln}(\mathrm{A}) 2\}=\operatorname{Do}(\mathrm{Pt} / \mathrm{e}) 0.638\{-0.148(\operatorname{Ln}(\mathrm{Pt} / \mathrm{e}) 2\}
$$

Where, The coefficient $\mathrm{D}_{\mathrm{o}}$ is function of remaining influencing parameter $\mathrm{P}_{\mathrm{a}} / \mathrm{e}$.

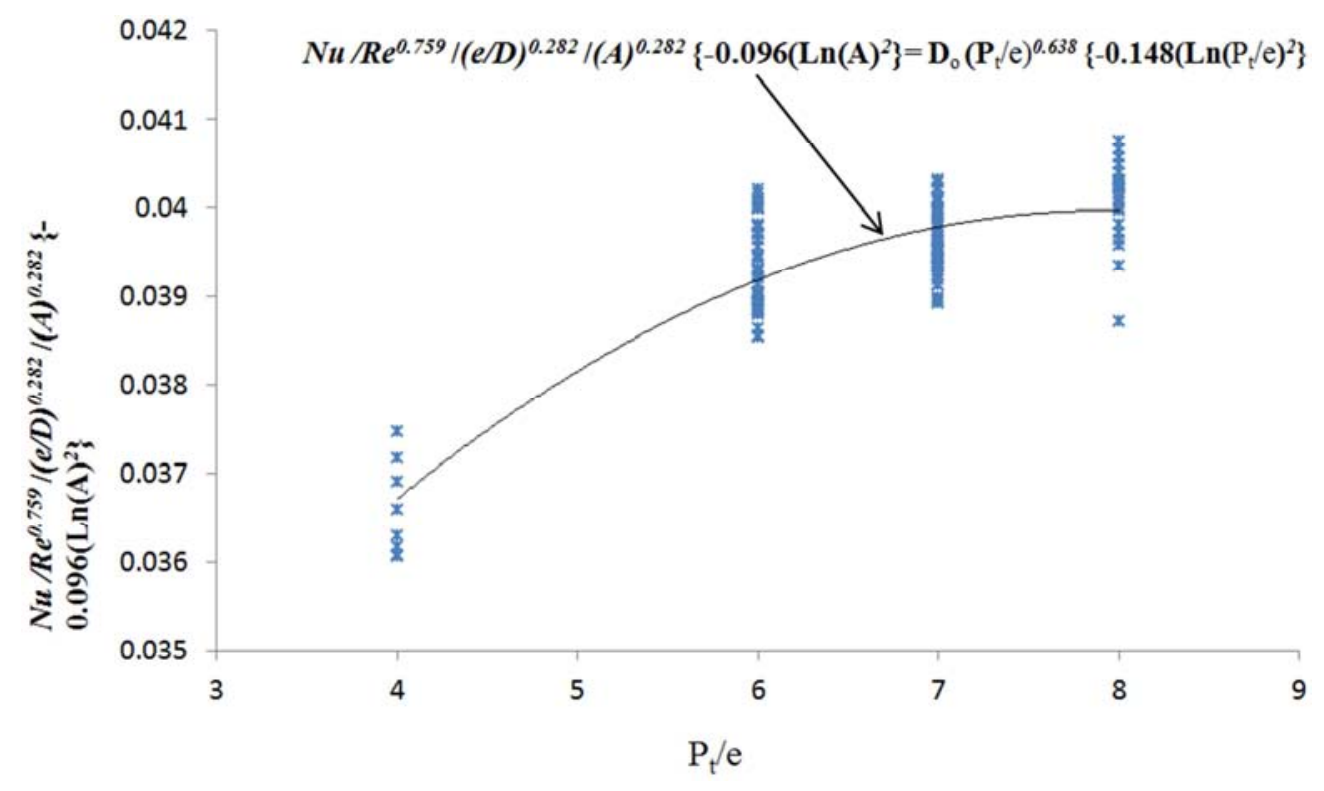

Figure 13. $\mathrm{Nu} / \mathrm{Re}^{0.759} /(e / D)^{0.282} /(A)^{0.282}\left\{-0.096\left(\operatorname{Ln}(A)^{2}\right\} V_{S} P_{t} e\right.$.

Now, taking the parameter Relative roughness pitch in Longitudinal Direction $\left(\mathrm{P}_{\mathrm{a}} / \mathrm{e}\right)$ into consideration, the value of $N u$ $/ R e^{0.759} /(e / D)^{0.282} /(A)^{0.282}\left\{-0.096\left(\operatorname{Ln}(\mathrm{A})^{2}\right\} /\left(\mathrm{P}_{\mathrm{t}} / \mathrm{e}\right)^{0.638}\left\{-0.148\left(\operatorname{Ln}\left(\mathrm{P}_{\mathrm{t}} / \mathrm{e}\right)^{2}=\left(\mathrm{D}_{\mathrm{o}}\right)\right.\right.\right.$ corresponding to all values of $\mathrm{P}_{\mathrm{a}} / \mathrm{e}$ are plotted, and has been shown in Figure 14.

Regression analysis to find best fit line through these points has been carried out and corresponding equation is as follows:

$\mathrm{Nu} / \operatorname{Re} 0.759 /(\mathrm{e} / \mathrm{D}) 0.282 /(\mathrm{A}) 0.282\{-0.096(\operatorname{Ln}(\mathrm{A}) 2\} /(\mathrm{Pt} / \mathrm{e}) 0.638\{-0.148(\mathrm{Ln}(\mathrm{Pt} / \mathrm{e}) 2\}=\mathrm{Eo}(\mathrm{Pa} / \mathrm{e})-0.04$ 


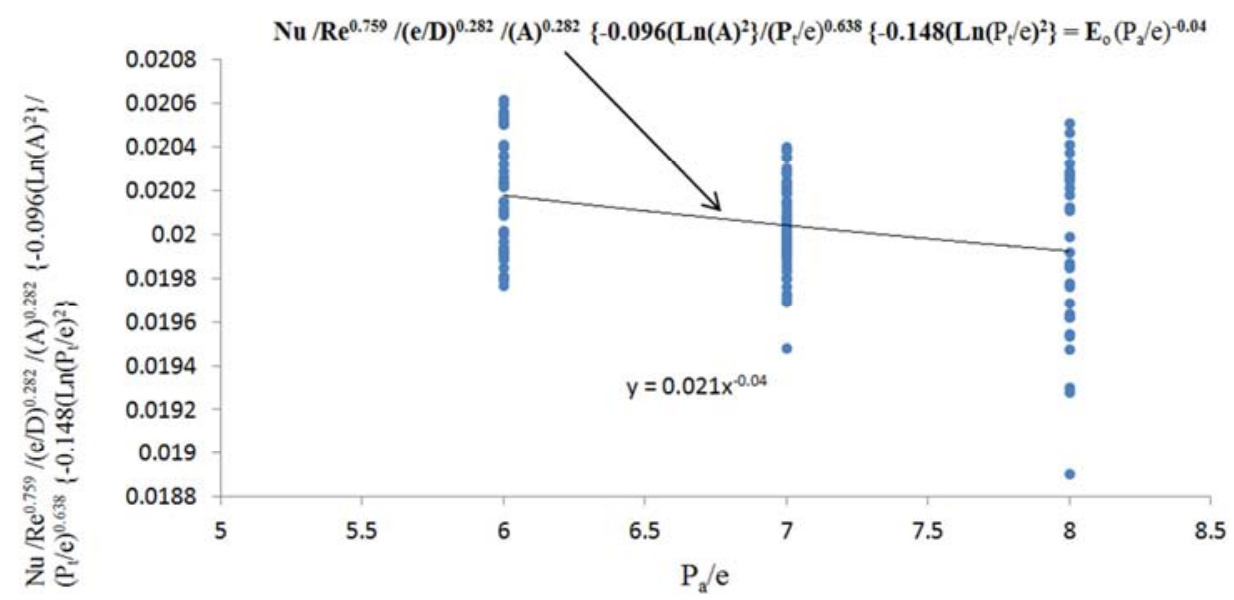

Figure 14. $\mathrm{Nu} / \operatorname{Re}^{0.759} /(e / D)^{0.282} /(A)^{0.282}\left\{-0.096\left(\operatorname{Ln}(A)^{2}\right\} /\left(P_{t} / e\right)^{0.638}\left\{-0.148\left(\operatorname{Ln}\left(P_{t} / e\right)^{2}\right\}\right.\right.$ VS $P_{a} / e$.

Based on the regression analysis final correlation for Nusselt number is as follows:

$$
\mathrm{Nu}=0.021 \operatorname{Re}^{0.759}\left(\frac{\mathrm{e}}{\mathrm{D}}\right)^{0.282} \mathrm{~A}^{0.536}\left(\frac{\mathrm{P}_{\mathrm{t}}}{\mathrm{e}}\right)^{0.638}\left(\frac{\mathrm{P}_{\mathrm{a}}}{\mathrm{e}}\right)^{-0.044}\left[\exp \left\{-0.096(\operatorname{Ln}(\mathrm{A}))^{2}\right\}\right]\left[\exp \left\{-0.148\left(\operatorname{Ln}\left(\frac{\mathrm{P}_{\mathrm{t}}}{\mathrm{e}}\right)\right)^{2}\right\}\right]
$$

The comparison between the values of Nusselt number calculated using developed correlation and Numerical simulation is shown in Figure 15. It is very clear from the figure that the found values are within $\pm 4 \%$ deviation which is reasonable and acceptable.

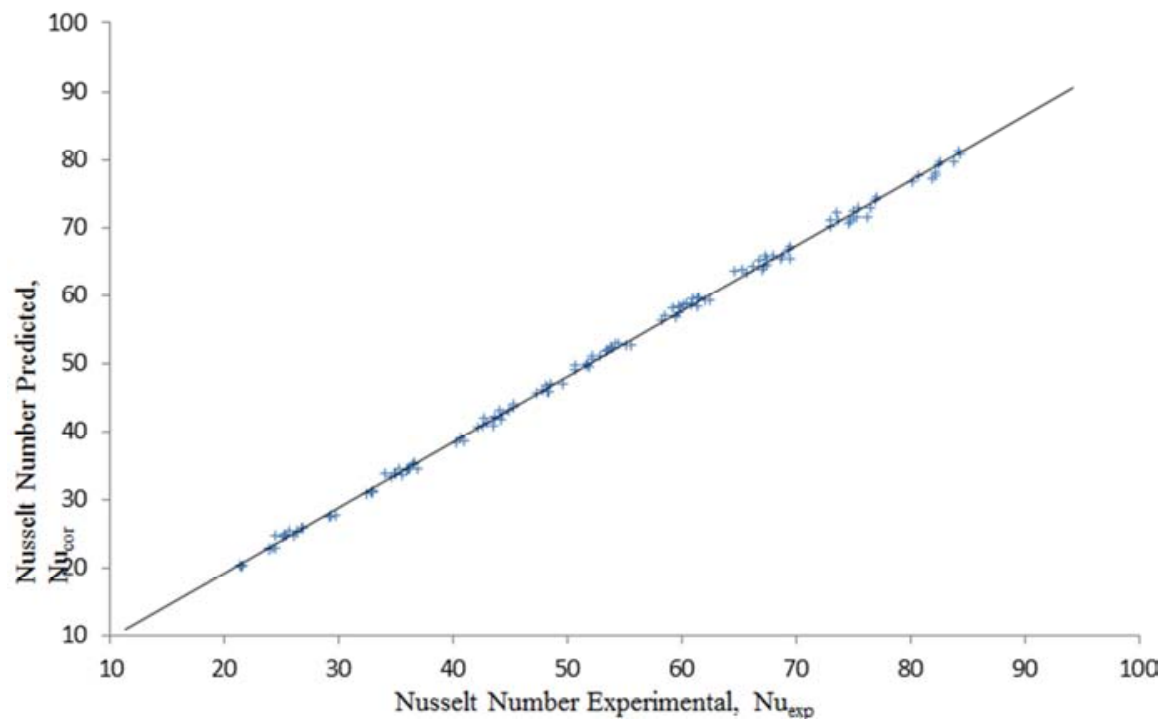

Figure 15. Comparison of predicted and experimental values of Nusselt Number.

\subsection{Correlations for Friction Factor}

Same procedure was fallowed for development of correlation for friction factor.

From the investigated simulation result it is very clear that the Nusselt number is fully dependent on roughness parameters studied.

Similar to the Nusselt number, friction factor is also dependent on roughness parameters. The parameters taken into consideration were, e/D, $\mathrm{P}_{\mathrm{a}} / \mathrm{e}, \mathrm{P}_{\mathrm{t}} / \mathrm{e}$, Aand the operating parameter Re. Therefore, the equation for the friction factor can be written as:

$$
F r=f(R e, e / D, P a / e, P t / e, A)
$$

Similarly, with the help of Microsoft excel a regression analysis has been done to develop statistical correlations covering all 136 simulation data found from CFD corresponding to all 17 artificially roughened absorber plates. The friction factor plotted as function of Reynolds number has been shown in Figure 16. The best fit equation for friction factor found from the Regression analysis is as follows:

$$
F r=A 1 R e-0.35
$$

Where, The coefficient $A_{1}$ is a function of other influencing parameterse/D, $\mathrm{P}_{\mathrm{a}} / \mathrm{e}, \mathrm{P}_{\mathrm{t}} / \mathrm{e}$ and $\mathrm{A}$. 


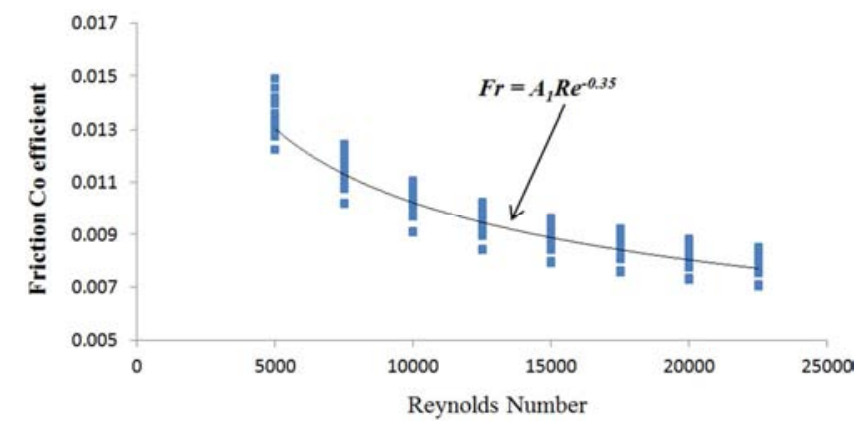

Figure 16. Friction factor vs. Reynolds number.
Now, considering relative roughness height (e/D) of roughness element, the value of $\mathrm{F}_{\mathrm{r}} /\left(\mathrm{Re}^{0.35}=\left(\mathrm{A}_{1}\right)\right.$ corresponding to all values of e/D are plotted in Figure 17.

Now, the regression analysis to find best fit line through these points has been carried out and corresponding equation is as follows:

$$
\mathrm{Fr} / \operatorname{Re}-0.35=B 1(e / D) 0.202
$$

Where, the coefficient $\mathrm{B}_{1}$ is a function of other remaining influencing parameters $\mathrm{P}_{\mathrm{a}} / \mathrm{e}, \mathrm{P}_{\mathrm{t}} / \mathrm{e}$ and $\mathrm{A}$.

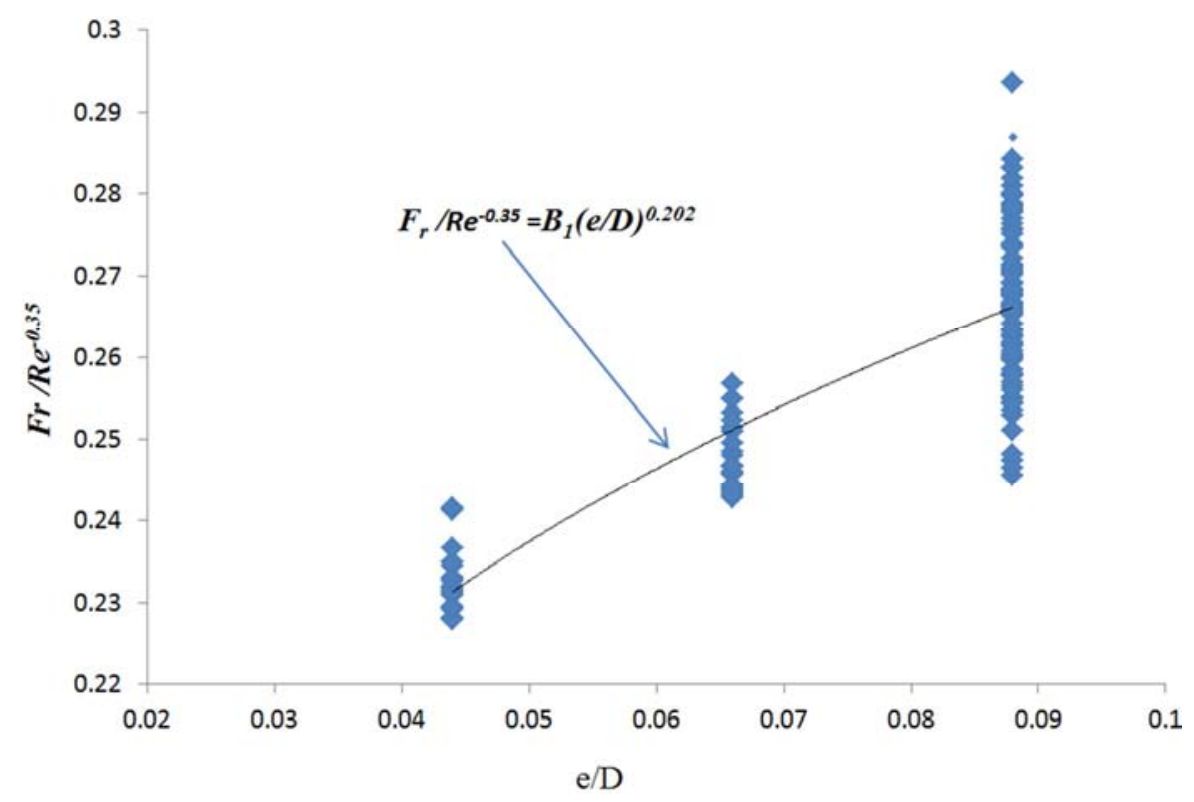

Figure 17. $F_{r} / \operatorname{Re}^{-0.35} V_{S}(e / D)$.

Now, considering arm length (A) of roughness, thevalue of $\mathrm{F}_{\mathrm{r}} / \mathrm{Re}^{-0.35} /(e / D)^{0.202}=B_{1}$ corresponding to all values of $\mathrm{A}$ are plotted in Figure 18.

Regression analysis to find best fit line through these points has been carried out and corresponding equation is as follows:

$$
\mathrm{Fr} / \operatorname{Re}-0.35 /(e / D) 0.202=C 1(A) 0.308\{-0.037(\operatorname{Ln}(\mathrm{A}) 2\}
$$

Where, the coefficient $\mathrm{C}_{1}$ is a function of other remaining influencing parameters $\mathrm{P}_{\mathrm{a}} / \mathrm{e}$ and $\mathrm{P}_{\mathrm{t}} / \mathrm{e}$.

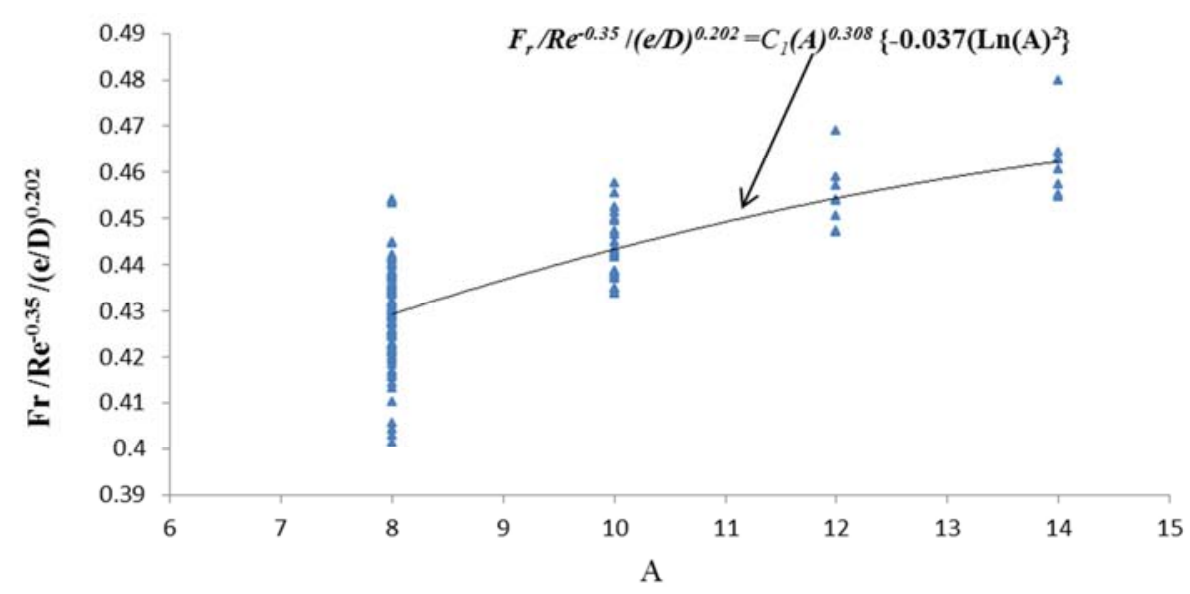

Figure 18. $F_{r} / R e^{-0.35} /(e / D)^{0.202} V s A$.

Now, considering Relative roughness pitch in Transverse Direction $\left(\mathrm{P}_{\mathrm{t}} / \mathrm{e}\right)$, the value of $\mathrm{F}_{\mathrm{r}} / \mathrm{Re}^{-0.35} /(\mathrm{e} / \mathrm{D})^{0.202} /(\mathrm{A})^{0.308}\{-$ 
$0.037\left(\operatorname{Ln}(\mathrm{A})^{2}\right\}=\mathrm{C}_{1}$ corresponding to all values of $\mathrm{P}_{\mathrm{t}} / \mathrm{e}$ are plotted in Figure 19.

Regression analysis to find best fit line through these points has been carried out and corresponding equation is as follows:

$$
\operatorname{Fr} / \operatorname{Re}-0.35 /(\mathrm{e} / \mathrm{D}) 0.202 /(\mathrm{A}) 0.308\{-0.037(\operatorname{Ln}(\mathrm{A}) 2\}=\mathrm{D} 1(\mathrm{Pt} / \mathrm{e}) 0.608\{-0.153(\mathrm{Ln}(\mathrm{Pt} / \mathrm{e}) 2\}
$$

Where, the coefficient $\mathrm{D}_{1}$ is a function of remaining influencing parameter $\mathrm{P}_{\mathrm{a}} / \mathrm{e}$.

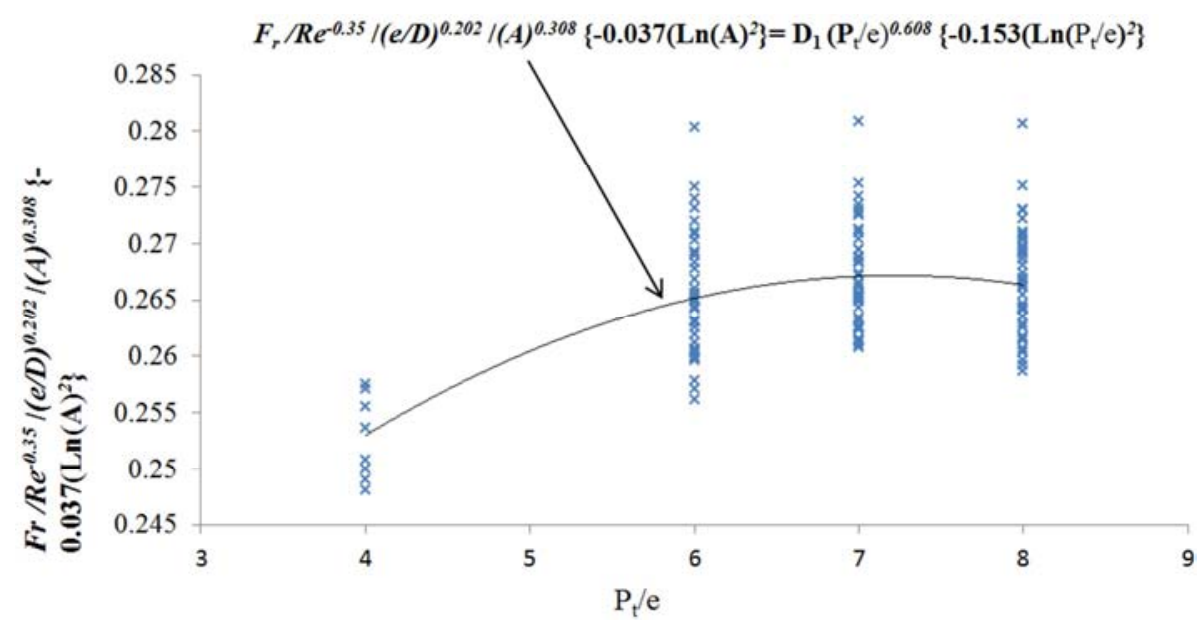

Figure 19. $F_{r} / \operatorname{Re}^{-0.35} /(e / D)^{0.202} /(A)^{0.308}\left\{-0.037\left(\operatorname{Ln}(A)^{2}\right\}\right.$ Vs $\left(P_{t} / e\right)$.

Now, consideringRelative roughness pitch in Longitudinal Direction $\left(\mathrm{P}_{\mathrm{a}} / \mathrm{e}\right)$, thevalue off $\mathrm{r}_{\mathrm{r}} / \mathrm{Re}^{-0.35} /(\mathrm{e} / \mathrm{D})^{0.202} /(\mathrm{A})^{0.308}\{-$ $0.037\left(\operatorname{Ln}(\mathrm{A})^{2}\right\} /\left(\mathrm{P}_{\mathrm{t}} / \mathrm{e}\right)^{0.608}\left\{-0.153\left(\operatorname{Ln}\left(\mathrm{P}_{\mathrm{t}} / \mathrm{e}\right)^{2}\right\}=\mathrm{D}_{1}\right.$ corresponding to all values of $\mathrm{P}_{\mathrm{a}} / \mathrm{e}$ are plotted in Figure 20.

Regression analysis to find best fit line through these points has been carried out and corresponding equation is as follows:

$$
\operatorname{Fr} / \operatorname{Re}-0.35 /(\mathrm{e} / \mathrm{D}) 0.202 /(\mathrm{A}) 0.308\{-0.037(\operatorname{Ln}(\mathrm{A}) 2\} /(\mathrm{Pt} / \mathrm{e}) 0.608\{-0.153(\mathrm{Ln}(\mathrm{Pt} / \mathrm{e}) 2\}=\mathrm{E} 1(\mathrm{~Pa} / \mathrm{e})-0.018
$$

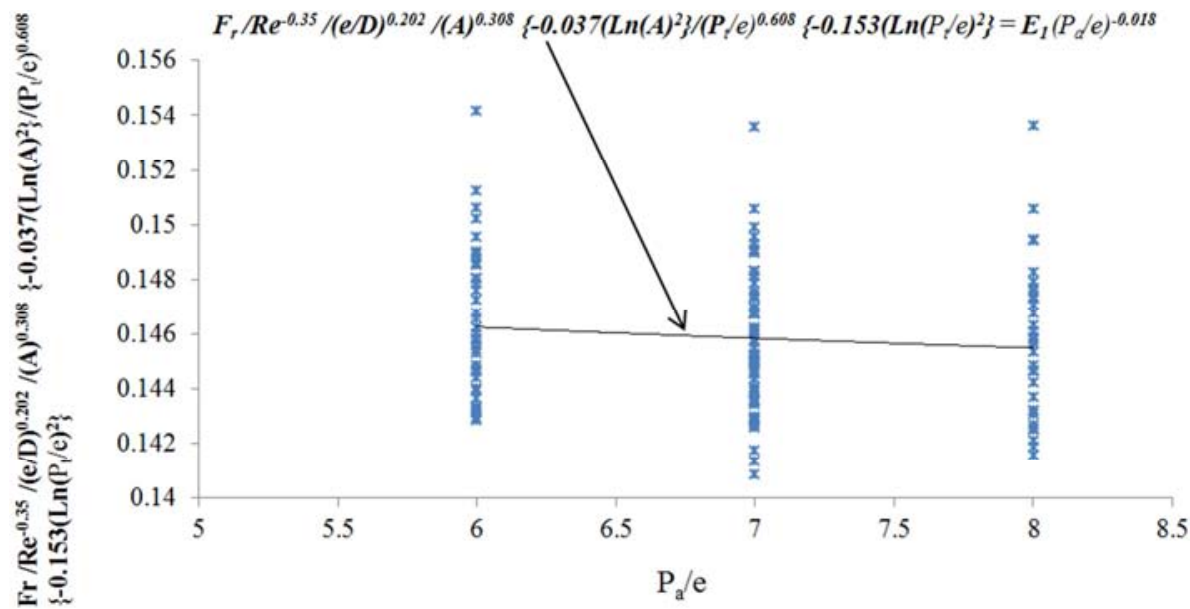

Figure 20. $F_{r} / \operatorname{Re}^{-0.35} /(e / D)^{0.202} /(A)^{0.308}\left\{-0.037\left(\operatorname{Ln}(A)^{2}\right\} /(P t / e)^{0.608}\left\{-0.153\left(\operatorname{Ln}(P t / e)^{2}\right\} V_{S}\left(P_{a} / e\right)\right.\right.$.

Based on the regression analysis final correlation for Friction factor is as follows:

$$
\operatorname{Fr}=0.151 \operatorname{Re}^{-0.35}\left(\frac{\mathrm{e}}{\mathrm{D}}\right)^{0.202} \mathrm{~A}^{0.308}\left(\frac{\mathrm{P}_{\mathrm{t}}}{\mathrm{e}}\right)^{0.608}\left(\frac{\mathrm{P}_{\mathrm{a}}}{\mathrm{e}}\right)^{-0.018}\left[\exp \left\{-0.037(\operatorname{Ln}(\mathrm{A}))^{2}\right\}\right]\left[\exp \left\{-0.153\left(\operatorname{Ln}\left(\frac{\mathrm{P}_{\mathrm{t}}}{\mathrm{e}}\right)\right)^{2}\right\}\right]
$$

The comparison between the values of Friction factor calculated using developed correlation and Numerical simulation is shown in Figure 21. It is very clear from the figure that the found values are within $\pm 5 \%$ deviation which is reasonable and acceptable. 


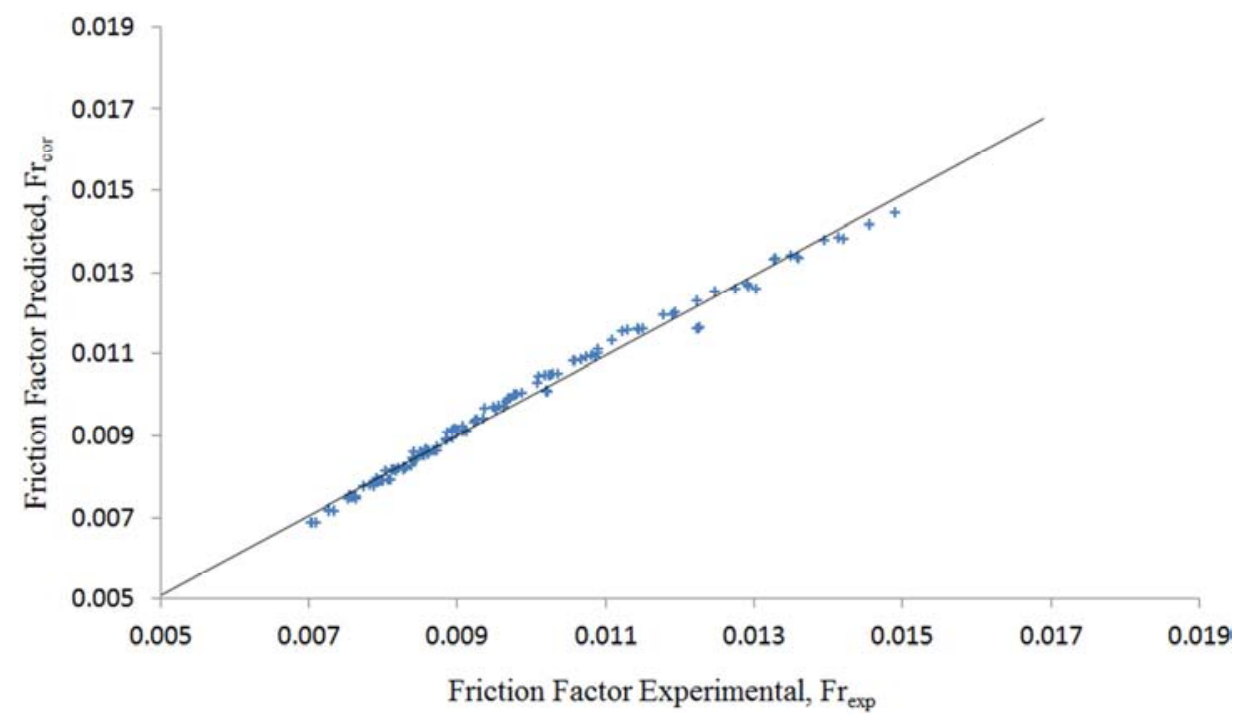

Figure 21. Comparison of predicted and experimental values of friction factor.

\section{Conclusion}

This paper presents a three-dimensional CFD investigation of the thermal hydraulic performance of the SAH having a rectangular duct with chamfered square roughness elements on the absorber plate. The major findings of the study are itemized below:

1. The thermal performance of the heater in presence of the chamfered square roughness elements is observed to be improved compared to the smooth duct based heater. The Nusselt number increases 1.23-1.54 times for the roughened heater compared to the smooth heater for the Reynolds number range used in the simulation.

2. The Nusselt number increases for the roughened absorber plate with increase in Reynolds number. The Nusselt number of the rough plate is in the range of $21.32-84.3 \mathrm{~W} / \mathrm{m}^{2} \mathrm{~K}$ and for the smooth plate in range of $17.4-61.8 \mathrm{~W} / \mathrm{m}^{2} \mathrm{~K}$.

3. The friction co-efficient is found to increase for the roughened absorber plate in comparison to the smooth plate. It is in the range of $0.0070-0.0149$ for the roughened plate, whereas $0.0066-0.0106$ for the smooth plate.

4. Application of roughness geometry in SAH duct increases the Nusselt number as well as friction factor in comparison to the smooth ducted heater. The Nusselt number increases with increase in the Reynolds number where as the friction factor decreases with increase in the Reynolds number for all sets of roughness geometry.

5. Correlation for Nusselt number and friction factor has been developed.

\section{Nomenclature}

L Solar air heater duct length, $\mathrm{mm}$

$\mathrm{H} \quad$ Solar air heater duct height, $\mathrm{mm}$

W Solar air heater duct width, $\mathrm{mm}$
W/H Aspect ratio

D The hydraulic diameter of the duct, $\mathrm{mm}$

e Roughness height of the element, $\mathrm{mm}$

A Arm length of the roughness element, mm

e/D Relative roughness height

Re Reynolds number

$\mathrm{P}_{\mathrm{a}} / \mathrm{e} \quad$ Relative roughness pitch in longitudinal direction, mm

$\mathrm{P}_{\mathrm{t}} / \mathrm{e} \quad$ Relative roughness pitch in transverse direction, $\mathrm{mm}$

$\mathrm{Nu}_{\mathrm{s}} \quad$ Nusselt number of smooth duct

$\mathrm{Nu}_{\mathrm{r}} \quad$ Nusselt number of roughened duct

$\mathrm{Fr}_{\mathrm{s}} \quad$ Friction factor for smooth duct

$\mathrm{Fr}_{\mathrm{r}} \quad$ Friction factor for roughened duct

I Heat flux, $\mathrm{W} / \mathrm{m}^{2}$

\section{References}

[1] Roy A, Hoque E Md. Performance analysis of double pass solar air heater with packed bed porous media in Rajshahi. AIP Conference Proceedings 1851, 020010 (2017); https://doi.org/10.1063/1.4984639

[2] Hachemi A. Thermal performance enhancement of solar air heaters, by a fan-blown absorber plate with rectangular fins. Int. J. Energy Res. 1995; 19: 567-577.

[3] Chabane F, Moummi N, Benramache S. Experimental study of heat transfer and thermal performance with longitudinal fins of solar air heater. J. Adv. Res. 2014; 5: 183-192.

[4] Chabane F, Moummi N, Benramache S, Bensahal D, Belahssen O. Collector efficiency by single pass of solar air heaters with and without using fins. Eng. J. 2012; 17: 43-55.

[5] Ibrahim Z, Ibarahim Z, Yatim B, Ruslan H Md. Thermal efficiency of single-pass solar air collector. AIP Conference Proceedings 1571, 90 (2013); doi: 10.1063/1.4858635.

[6] Kasayapanand N, Kiatsiriroat T, Vorayos N. Enhanced heat transfer in a solar air heater with double-flow configuration by electro hydrodynamic technique. J. Enhanced Heat Transf. 2006; 13: 39-52. 
[7] Rajpoot SS, Koli DK. CFD analysis of solar air heater duct with rectangular rib surface. Int. J. Eng. Trends Tech. 2013; 4: 3006-3011.

[8] Dogra S. Effect of artificial roughness on thermal and thermohydraulic efficiency in rectangular duct of a double pass solar air heater by using transverse ribs on the absorber plate. Int. J. Mod. Eng. Res. 2013; 3: 2271-2274.

[9] Kumar TS, Thakur NS, Kumar A, Mittal V. Use of artificial roughness to enhance heat transfer in solar air heaters - a review. J. Energy Southern Africa 2010; 21: 35-51.

[10] Vyas AA, Shringi D. CFD based thermal efficiency analysis of solar air heater with smooth plate and perforated plate. Imp. J. Interdisc. Res. 2017; 3: 415-422.

[11] Tapas V, Sao AK, Sharma P. Computational analysis of an artificial roughened surface of solar air heater. Int. J. Innovative Res. Sci. Eng. Tech. 2015; 4: 12205-12212.

[12] Prasad BN, Saini JS. Effect of artificial roughness on heat transfer and friction factor in a solar air heater. Solar Energy 1988; 41: 555-560.

[13] Karwa R, Bairwa RD, Jain BP, Karwa N. Experimental study of the effects of rib angle and discretization on heat transfer and friction in an asymmetrically heated rectangular duct. J. Enhanced Heat Transf. 2005; 12: 343-55.

[14] Arjumand Rasool, Adnan Qayoum. Numerical analysis of heat transfer and friction factor in two-pass channels with variable rib shapes. International Journal of Heat and Technology. 36 91) 2018, 40-48. https://doi.org/10.18280/ijht.360106.

[15] ANSYS FLUENT 13.0 Theory Guide, ANSYS Inc., 2010. 